\title{
A cross sectional study of epidemiology corresponding to refractive errors in school going children in urban areas of Hyderabad
}

\author{
Mohammed R. ${ }^{1}$, Khan M.A. ${ }^{2}$, Reddy U.N. ${ }^{3}$ \\ ${ }^{1}$ Dr. Rashwan Mohammed, Assistant Professor, ${ }^{2}$ Dr M. Ahmedullah Khan, Assistant Professor, ${ }^{3}$ Dr. U. Narayan Reddy \\ Professor \& HOD, all authors are affiliated with Department of Pediatrics, Princess Esra Hospital, Deccan College of \\ Medical Sciences, Hyderabad, Telangana., India \\ Corresponding Author: Dr. M. Ahmedullah Khan, Assistant Professor, Department of Pediatrics, Princess Esra \\ Hospital, Deccan College of Medical Sciences, Hyderabad, Telangana, India. E-mail: ahmedkhan67353@gmail.com
}

\begin{abstract}
Introduction: There are estimated to be 1.4 million children in the world, $75 \%$ of whom live in low-income countries. Approximately, $80 \%$ of blindness is avoidable. The prevalence of the childhood blindness is estimated from 0.3 per 1000 children in the wealthy region of the world to 1.5 per 1000 children in the poorer countries/regions. Methodology: The study was conducted From January to June 2018, in Princess Esra Hospital, a 1000 bedded teaching hospital, situated in Hyderabad, providing specialized tertiary level health care services to all strata of people. Children studying in the high school in Government and Private school were selected for the present study, the children selected has a history of overall good health. Aims and Objectives: This planned study has been attempted with the accompanying targets, to concentrate on the predominance of refractive errors in school going children and to assess the etiologic proof. Results: The total of 540 children were included in the study with the history of overall good health, which includes 82 females and 25 males diagnosed with refractive errors, shows that prevalence of refractive errors are more in female than compare to males. Conclusion: In this study, it has been recorded that $19.8 \%$ of the screened school children have refractive errors. The results showed significant statistical difference regarding the prevalence of refractive errors between children of government and private schools.
\end{abstract}

Keywords: Refractive error, School children, Female, Hyderabad

\section{Introduction}

According to World Health Organization in 2004, it was estimated that more than 161 million people were visually impaired worldwide, of whom 124 million people had low vision and 37 million were blind [1]. These figures were estimated in 2002 and did not include uncorrected refractive error. Uncorrected refractive error in children and adults has short and long-term effects.

The inclusion of this would have raised these figures to 314 million people to be visually impaired. Cataract is the main cause of adult blindness and uncorrected refractive error ranks second [2]. One of the five priorities of -VISION 2020 The Right to Sight is to prevent and to eliminate unnecessary blindness and to provide good vision among children including treatment of refractive error and to pay more attention [3]. For

Manuscript received: $2^{\text {nd }}$ December 2018

Reviewed: $12^{\text {th }}$ December 2018

Author Corrected: $17^{\text {th }}$ December 2018

Accepted for Publication: $22^{\text {nd }}$ December 2018 children, refractive error is another priority in terms of visual disability that needs treatment. At the same time focus on refractive services as part of primary health care and school services, and low-cost production of spectacles are highly desirable [4]. One of the leading causes of blindness is due to visual impairment caused by refractive error in children and accounting for $3 \%$ of blindness in southern Indian school children and much higher (prevalence of myopia $21.6 \%$ and hyperopia $2.7 \%$ ) in China [5].

Refractive error can have a significant impact on a child's life affecting their future employment, and eventually leading to social stigmatization [6]. WHO and IAPB global initiative launched Vision 2020 in 1999 to eliminate the main causes of avoidable blindness by the year 2020 by giving priorities on cataract, refractive errors, trachoma, onchocerciasis and certain causes of childhood blindness [7]. There are estimated to be 1.4 million children in the world, $75 \%$ 
of whom live in low-income countries [8]. Approximately, $80 \%$ of blindness is avoidable [4]. The prevalence of the childhood blindness is estimated from 0.3 per 1000 children in the wealthy region of the world to 1.5 per 1000 children in the poorer countries/regions [9].

Five hundred thousand children become blind each year, 1 per minute, but half of them die within one or two years of becoming blind [6]. Approximately, 70 million blind person years are caused by childhood blindness [10].

The blind person years are the number of years lived with blindness by a blind person. The high number of blind years resulting from blindness during childhood is one of the reasons why childhood blindness is a priority of the WHO/IAPB, VISION-2020 the Right to Sight [11]. Refractive errors are treatable with low cost spectacles and if untreated, usually lead to visual disabilities in children [12].

As because of school children are very unaware of refractive errors and school screening is recommended [5]. Since 1988, magnitude of refractive error and visual loss due to refractive errors in children was little known and to know about it some specific surveys was done to assess the refractive error in school children [13].

Though the causes, types and magnitude of refractive errors varies from region to region, very little is known about the magnitude of visual loss due to refractive error in children. Different studies have shown that myopia, a type of refractive error is more common in children and in older age children group in urban areas in Asia [14].

\section{Materials and Methodology}

Place of Study: The study conducted in Hyderabad city. Study population consisted of high school students studying from class 6th to class 10th in a government high school and a private school.

A total of 540 students of both schools (270 from each) with good general health were included in the study.

The study was conducted From January to June 2018, Automated and cycloplegic refraction, where needed, were carried out at the Ophthalmology Department of ophthalmology at princess Esra hospital shahlibanda, a 1000 bedded teaching hospital, situated in Hyderabad, providing specialized tertiary level health care services to all strata of people.
Type of Study: A Cross-sectional Prospective study

Sampling Methods: Simple random sampling technique is followed in the present study.

Sample Collection and Analysis: Details of the students like history impaired vision, unable to se board clearly etc, were recorded in the predesigned and pretested Performa which consists history of refractive errors in family, History of any pre-existing medical condition, prolonged indulgence in video games, studying in dim light (<100watts), Complete Eye examination, Reason for reduced vision in RE/LE, any congenital structural defects in eyes, Diagnosis Of Refractive Error.

All these parameters were investigated, recorded and tabulated.

Finally a comparison was made between the age of Children's correlating with studying in dim light, use of video games, study in low light etc, in contrast with type of refractive errors.

Later the results were calculated and recorded in terms of means \pm standard deviation.

\section{Inclusion criteria}

1) All the students from class 6th to 10 th in the selected schools.

2) Students with overall good health condition

3) Students with negative history for viral profile.

4) Student who was prescribed glasses but had not used them regularly.

\section{Exclusion criteria}

1) Students studying below 6th class and those already using glasses regularly were excluded.

2) Each school was screened over a period of six months (only in working days) in which the students were examined by assessing visual acuity from a Standard Snellen Chart.

3) Those having visual acuity less than $6 / 12$ in one or both eyes were tested for the presence or otherwise of a refractive error by pin hole test.

4) Those showing improvement with pinhole (indicating refractive error) were then subjected toretinoscopy and subjective refraction are excluded. 
Statistical Analysis: Sample size was calculated from Stat_calc utility of the Epi Info software, version 3.2, based upon the following assumptions:

- Population size of 540 ,

- Confidence interval 95\%,

- Expected frequency to be $20 \%$.

Ethical Approval: approval from institutional review board was obtained before the study was initiated.

\section{Aims and Objectives}

1) To determine the prevalence of visual impairment due to refractive errors in school going children from $6^{\text {th }}$ to $10^{\text {th }}$ standard.

2) To investigate the influence of some factors on the problem of low vision due to refractive errors.

\section{Results}

It was observed that only $3.3 \%$ of the children of high schools are more than 15 years of age.

The majority of the children belong to age group 12-14.

This constitutes $66 \%$ of the group. It is this vulnerable group that is faced with the impending perils of undetected reduction in vision resulting in reduction of working capacity and in certain cases leading to blindness or visual impairment which can well be avoided.

In our study the results are significantly different between the two types as refractive errorsoccur more in private schools as compared to government schools $(\mathrm{p}<0.05)$. Mean age 13.00 years Standard deviation \pm 1.39 as shown in Table 1 .

Table-1: Distribution of school children according to age.

\begin{tabular}{|c|c|c|}
\hline Age & Frequency & Percentage \\
\hline 11 & 91 & $16.9 \%$ \\
\hline 12 & 118 & $21.9 \%$ \\
\hline 13 & 130 & $24.1 \%$ \\
\hline 14 & 110 & $20.4 \%$ \\
\hline 15 & 73 & $23.5 \%$ \\
\hline 16 & 18 & $3.3 \%$ \\
\hline Total & $\mathbf{5 4 0}$ & $\mathbf{1 0 0 . 0 \%}$ \\
\hline
\end{tabular}

School wise distribution of refractive errors- Refractive errors indicates very strong relation-ship between watching television closely (i.e. less than 10 feet for a standard $21 \mathrm{~K} \mathrm{TV}$ ) and refractive errors. 44 students found to have refractive errors from government school while 63 are from the private school.

However it must be clearly understood that proper sequence of events has to be established by further studies whether this is a cause or an effect

Table-2: Correlation between family history and refractive error Vs non refractive errors.

\begin{tabular}{|c|c|c|c|}
\hline \multirow{3}{*}{$\begin{array}{l}\text { Family } \\
\text { History }\end{array}$} & & Refractive Error & No Refractive Error \\
\cline { 2 - 4 } & Positive & 61 & 283 \\
\cline { 2 - 4 } & Negative & 46 & $\mathbf{4 3 3}$ \\
\cline { 2 - 4 } & Total & $\mathbf{1 0 7}$ & 150 \\
\hline
\end{tabular}

Chi $2\left(\mathrm{X}^{2}\right)=18.03$

d.f. $=1 \quad \mathrm{p}<0.00002$

The table 2 shows that 61 out of 107 students who have refractive errors have a positive history of wearing glasses in their families and indicates a very strong relationship between refractive errors and heredity or familial factors. 
Table-3: Correlation between watching TV closely with refractive errors vs non refractive errors.

\begin{tabular}{|l|l|l|l|}
\hline \multirow{2}{*}{\begin{tabular}{l} 
WV \\
\multirow{3}{*}{ closely }
\end{tabular}} & Refractive Error & 19 & No Refractive Error \\
\cline { 2 - 4 } & For 1-5+ Year & 88 & 5 \\
\cline { 2 - 4 } & None to less than 1 Year & 88 & 428 \\
\cline { 2 - 4 } & Total & $\mathbf{1 0 7}$ & $\mathbf{4 3 3}$ \\
\hline
\end{tabular}

Chi $2\left(X^{2}\right)=55.69$

d.f. $=1 \quad p<0.0000$

A study by Tan et al [15] shows that there is and evidence which shows strong relationship between short distance TV watching and the development of RE as shown in Table 3.

Table-4: Prolonged indulgence in computer/ video games.

\begin{tabular}{|l|l|l|l|}
\hline Prolonged & & Refractive Error & No- refractive. error \\
indulgence $\begin{array}{l}\text { in } \\
\text { computer/ video } \\
\text { games }\end{array}$ & $1-5+$ Year & 17 & 21 \\
\cline { 2 - 4 } & None to less than 1 Year & 90 & 422 \\
\cline { 2 - 4 } & Total & $\mathbf{1 0 7}$ & $\mathbf{4 3 3}$ \\
\hline
\end{tabular}

There is a significant statistical difference between little or no computer or video game use (none to $<1$ year) and prolonged use thereafter it (1-5years or more).

This is in accordance with other studies e.g. the study by Seet et al in Singapore [15].

This could be called not a direct factor but an intermediate factor attributed to changing "environmental conditions" \& having higher education, near work-related occupations involving computers etc and greatly increased family income in table4.

Table-5: Association with close study habits at a distance less than 12 inches

\begin{tabular}{|c|c|c|}
\hline Close Study Habits & Refractive Error & No Refractive Error \\
\hline $1-5+$ Years & 18 & 427 \\
\hline None to less than 1 year & 89 & $\mathbf{4 3 3}$ \\
\hline Total & $\mathbf{1 0 7}$ & 6 \\
\hline
\end{tabular}

Chi $2\left(X^{2}\right)=48.14$

d.f. $=1$

$p<0.005$

There appears to be a very strong relationship between close study and refractive errors. Forour purposes we have defined a cutoff point of 12 inches as minimum distance for reading as shown in Table 5 .

Table-6: Uncorrected visual acuity right and left eye

\begin{tabular}{|c|c|c|c|c|}
\hline \multirow{2}{*}{ Visual Acuity } & Frequency & Percent & Frequency & Percent \\
\cline { 2 - 5 } & \multicolumn{2}{|c|}{ Right eye } & 16 & $3.0 \%$ \\
\hline Severe decrease (<6/60) & 19 & $3.4 \%$ & 24 & $4.4 \%$ \\
\hline Moderate decrease (6/24-6/36) & 18 & $3.3 \%$ & 67 & $12.4 \%$ \\
\hline Mild decrease (6/12-6/18) & 70 & $13.2 \%$ & 433 & $80.1 \%$ \\
\hline Normal to borderline (6/6-6/9) & 433 & $80.1 \%$ & $\mathbf{5 4 0}$ & $\mathbf{1 0 0 . 0} \%$ \\
\hline Total & $\mathbf{5 4 0}$ & $\mathbf{1 0 0 . 0} \%$ & & \multicolumn{2}{c|}{ Left eye } \\
\hline
\end{tabular}


The table 6 above shows that $80 \%$ (433/540) of the children screened are normal for the right eye screening, $13.2 \%$ of the children shows mild level of refractive errors, while moderate and severe accounts for the $6.7 \%$ which needs immediate medical attention as the left eye refractive errors also resembles the nearly equal that of right eye as shown in table 6 above.

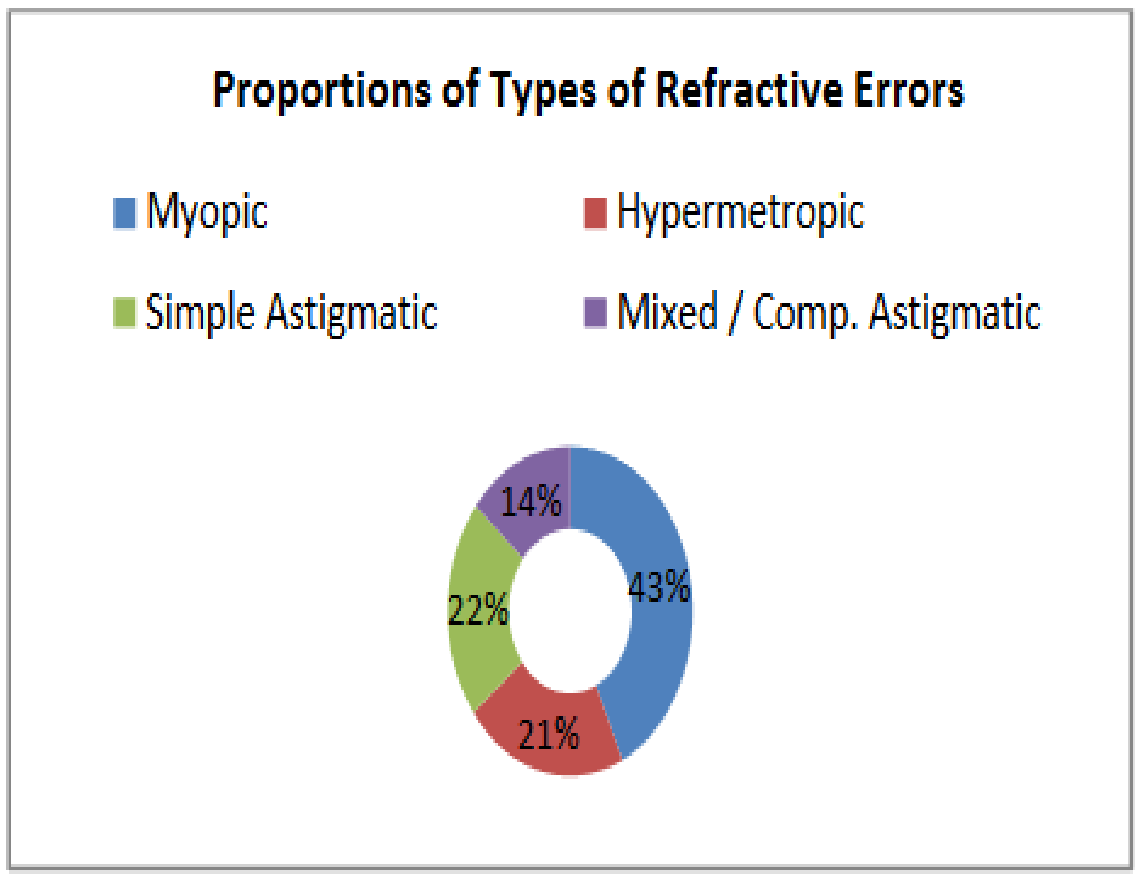

Fig-1: Proportions of types of refractive errors.

There were 46/107 (43\%) students who had myopia. Hence it was the most common refractive error followed by astigmatism (both simple as well as compound / mixed) which was 38/107 (36\%). Hypermetropia was the least common being $21.5 \%$ of the total $(23 / 107)$ as shown in fig 1 .

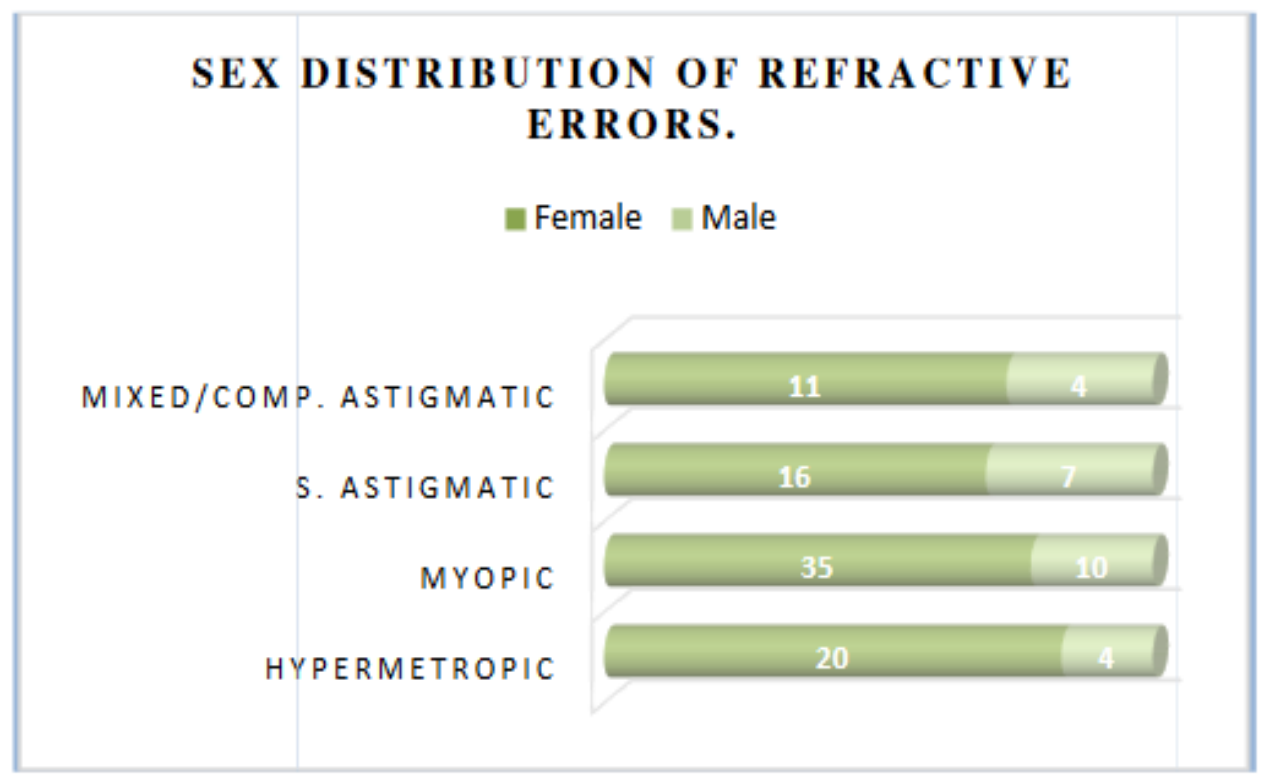

Fig-2: Sex distribution of refractive errors 
The above fig 2 shows that females are more prone to refractive errors than male counterpart. hence its is required that the females shall be screened for the refractive errors every 6 months.

This is manifested by total number of children where full correction was not possible despite ensuring the absence of any discemible organic pathology of the eye.

There were a total of 12 out of 107 children with refractive errors (11.2\%) in our study where full correction could not be achieved due to amblyopia due to uncorrected refractive errors.

\section{Discussion}

Refractive errors in the school children are the commonest clinical manifestation, which ranges from insignificant functional causes to potentially fatal pathologies.

The clinical presentations of our study were compared to that of the study by trivedi et al shows that in rural and urban area of Gujarat in the year 2006 reported that $66 \%$ of urban children and $8.5 \%$ of rural children had visual impairment as a cause of refractive error and prevalence of myopia (in the age group b/w 7-15yrs) is $4.1 \%$ and $7.4 \%$ in rural and urban area respectively and prevalence of hypermetropia (in the age group 7-15yrs) is $0.78 \%$ and $7.7 \%$ in urban and rural area respectively [16], while our study reveals the mean average age of the children is 13 years noted in majority of the refractive errors, $43 \%$ (46/107) being more prevalent in age group 12-15.

Astigmatism (simple as well as compound/mixed) was the next commonest, being $36 \%$ (38/107) of the total.

Hypermetropia common in age group 11-14 years and is the least common $(23 / 107$ or $21 \%)$. It is common in younger age groups after which the prevalence starts declining.

The refractive errors are high in our study when compared to that of A study done by Sharma, et al on magnitude of refractive errors among school children in a rural block of Haryana reported that out of 1265 children (6-15yrs), 172 children(13.6\%) were found to have defective vision $(<6 / 9)$.

Myopia in one eye $-22(1.74 \%)$, in both eyes$131(10.36 \%)$. Hyperopia in one eye-2(0.16\%), in both eyes-17 (1.34). myopia, Hyperopia, astigmatism in girls were more (23.7\%) than in boys (12.2\%). Myopia and astigmatism was more in higher age groups and prevalence of hyperopia was more in lower age groups17.

While our study shoes that $80 \%$ (433/540) of the children screened are normal for the right eye screening,
$13.2 \%$ of the children shows mild level of refractive errors, while moderate and severe accounts for the $6.7 \%$ which needs immediate medical attention as the left eye refractive errors also resembles the nearly equal that of right eye and also states that females are more prone to refractive errors than male counterpart.

A study by Sonam sethi et al in the school children (7$15 \mathrm{yrs})$ of Ahmedabad city reported that $25.32 \%$ of students were found to be having refractive errors. Of these $47 \%$ were female \& $53 \%$ were boys.

Myopia was seen in $63.5 \%$, Hypermetropia in $11.2 \%$ and Astigmatism in $20.4 \%$ [18].

Compared to our study which shows that 12 out of 107 children with refractive errors (11.2\%) in our study where full correction could not be achieved due to amblyopia due to uncorrected refractive errors also in our study 107 out of 540 (19.8\%) schoolchildren had refractive errors.

Of these 44 out of 270 were in school children belonging to government school depicting a prevalence of $16.3 \%$, whereas 63 out of $270(23.33 \%)$ were in children belonging to private schools showing a prevalence of $23.33 \%$.

\section{Conclusion}

1) The results showed significant statistical difference regarding the prevalence of refractive errors between children of government and private schools.

2) $16.3 \%$ of the children belongs to government school showed refractive errors while private school stands with $22.3 \%$ of the children with refractive errors these resembles that the students going to private schools should be adequately screened and these directly links to the use of computers and videogames It is recommended that the children going to private schools should be given very limited time with required distance from the computers during playing video games and watching tv or computers. 
3) Myopia was the commonest refractive errors found in diagnosed school children, Hence Delaying in the Screening of refractive errors accumulate the high risk of getting it.

Hence it is recommended for the parents to get their children screened for the Refractive errors timely to avoid late diagnosis.

4) General Contribution factors includes socioeconomic status of parents, living style \& habits should be changed to avoid the Refractive errors.

5) Females are more prone to refractive errors than male counterpart henceits is required that the females shall be screened for the refractive errors every 6 months.

\section{What this study add to existing knowledge?}

Research of the prevalence of myopia for the duration of the past one hundred years lead us to add more to the present knowledge that, amongst children there has been the prevalence of myopia in selected populations of school children and university-eligible teens.

an exception to this is that excessive myopia appears to be more in children going to schools that links with video games, computers and watching Tv's.

\section{References}

1. Resnikoff S, Pascolini D, Etya'ale D, et al. Global data on visual impairment in the year 2002. Bull World Health Organ. 2004 Nov;82(11):844-51. Epub 2004 Dec 14. DOI:/S0042-96862004001100009.[pubmed]

2. Resnikoff S, Pascolini D, Mariotti SP, Global magnitude of visual impairment caused by uncorrected refractive errors in 2004. Bull World Health Organ. 2008 Jan;86(1):63-70.[pubmed]

3. Gilbert C, Foster A. Blindness in children: control priorities and research opportunities. Br J Ophthalmol. 2001 Sep;85(9):1025-7.[pubmed]

4. Thylefors B. A global initiative for the elimination of avoidable blindness. Community Eye Health. 1998; 11(25):1-3.[pubmed]

5. World Health Organization, Elimination of avoidable visual disability due to refractive error Report of an informal planning meeting WHO/PBL/00.79 pp: 6-10.
6. World Health Organization, Geneva. Preventing blindness in Children: Report of a WHO/IAPB Scientific meeting, Hyderabad, India; 13-17 April, 1999; 13-14 (WHO_PBL_00.77).

7. World Health Organization, The State of the World's Sight, 2005. VISION 2020: The Right to Sight. 19952005.

8. Gilbert, C; Foster, A (2001) Childhood blindness in the context of VISION 2020 - The Right to Sight. Bulletin of the World Health Organization, 79 (3). pp. 227-32. ISSN 0042-9686

9. Gilbert CE, Anderton L, Dandona L, et al. Prevalence of visual impairment in children: a review of available data. Ophthalmic Epidemiol. 1999 Mar;6(1): 73-82.[pubmed]

10. Childhood cataract: magnitude, management, economics and impact. Shamanna BR, Muralikrishnan R eds. Community Eye Health. 2004;17(50):17-8.

11. World Health Organization. Programme for the Prevention of Blindness and Deafness. (2000). Global initiative for the elimination of avoidable blindness. Geneva : World Health Organization. http:// www.who. int/iris/ handle/10665/63748

12. Padhye S A et al. Prevalence of uncorrected refractive error and other eye problems among urban and rural school children. Middle East African Journal of ophthalmology. 2009; 16(2) 69-74.

13. Foster A, Gilbert C, Johnson G. Changing patterns in global blindness: 1988-2008. Community Eye Health. 2008 Sep;21(67):37-9.[pubmed]

14. Gilbert C, Muhit M. Twenty years of childhood blindness: what have we learnt?, Community Eye Health Journal 20th Anniversary edition. 2008; 21(67): 46-47.

15. Seet B, Wong TY, Tan DT, et al. Myopia in Singapore: taking a public health approach. $\mathrm{Br} \mathrm{J}$ Ophthalmol. 2001 May;85(5):521-6.[pubmed]

16. Bhatt, Janardhanl, Trivedi, Vevik, Sundeep, Prevalence of refractive error in children (age pp 7-15 years) of rural \& urban area of Gujarath; A population based study. Journal of Applied basic medical sciences, 2006,8(1);128-135. 
17. Magnitude of refractive errors among school children in a rural block of Haryana. Sharma Seema, B.M. Vashist, Dept. of Community Medicine, PGIMS. International Journal of Epidemiology 2009;Vol.6, Pg 1-5. DOI: $10.5580 / 1 \mathrm{e} 5 \mathrm{f}$
18. Sethi s, Kartha G. P, prevalence of refractive errors in school children of Ahamedabad city. Ind J conn med 2000;25(4);181-183

\section{How to cite this article?}

Mohammed R., Khan M.A., Reddy U.N. A cross sectional study of epidemiology corresponding to refractive errors in school going children in urban areas of Hyderabad. Int J Pediatr Res. 2018;5(12):617-624.doi:10.17511/ijpr.2018.i12.03. . Int J Pediatr Res. 2018;5(12):617-624.doi:10.17511/ijpr.2018.i12.03. 